\title{
Laser Therapy in the Treatment of Dentine Hypersensitivity
}

\author{
Thereza Christinna Cellos Gonçalves Pinheiro LADALARDO ${ }^{1}$ \\ Antonio PINHEIRO ${ }^{2}$ \\ Roberto Augusto de Carvalho CAMPOS ${ }^{1}$ \\ Aldo BRUGNERA JÚNIOR ${ }^{3}$ \\ Fátima ZANIN ${ }^{3}$ \\ Pedro Luiz Mangabeira ALBERNAZ ${ }^{1}$ \\ Luc Louis Maurice WECKX ${ }^{1}$ \\ ${ }^{1}$ Federal University of São Paulo - UNIFESP - EPM, São Paulo, SP, Brazil \\ ${ }^{2}$ Laser Center, School of Dentistry, Federal University of Bahia, Salvador, BA, Brazil \\ ${ }^{3}$ Laser Center, Camilo Castelo Branco University, São Paulo, SP, Brazil
}

\begin{abstract}
Cervical dentine hypersensitivity is the most frequent complaint among reported odontalgias. Thus, this study evaluated the effectiveness of two types of lasers ( $660 \mathrm{~nm}$ wavelength red, and $830 \mathrm{~nm}$ wavelength infrared) as dentine desensitizers, as well as both the immediate and late therapeutic effects in individuals 25 to 45 years of age. A total of 40 teeth with cervical exposure were treated in 4 sessions. They were divided into 2 groups according to treatment. A $660 \mathrm{~nm}$ wavelength red diode laser and an $830 \mathrm{~nm}$ wavelength infrared diode laser were used. Dentine sensitivity to cold nociceptive stimulus was evaluated by means of a pain numeric scale from zero to 10 before each treatment session, at 15 and $30 \mathrm{~min}$ after irradiation, and in a follow-up period of 15, 30 and 60 days after the end of treatment. Significant levels of dentinal desensitization were only found in patients ranging in age from 25 to 35 years. The 660 $\mathrm{nm}$ red diode laser was more effective than the $830 \mathrm{~nm}$ infrared laser and a higher level of desensitization was observed at the 15 and 30 minute post-irradiation examinations. The immediate and late therapeutic effects of the $660 \mathrm{~nm}$ red diode laser were more evident in 25-35-year-old patients compared with those of the $830 \mathrm{~nm}$ infrared diode laser, in terms of the different age groups.
\end{abstract}

Key Words: laser therapy, dentine hypersensitivity, dentine pain.

\section{INTRODUCTION}

Dentine hypersensitivity is prevalent amongst a large portion of individuals 30 to 40 years of age. It causes oral discomfort generated by pain, leads to nutritional deficiency due to dietary restrictions in some individuals. The nociceptive stimulus commonly reported in the majority of cases is that of cold, followed by the mechanical stimulus of toothbrushing and the chemical stimulus of diet with a high concentration of sugar (1).

Pain of dentinal origin is sharp, located, and of short duration. The hydrodynamic theory proposed by Brännströn e Aström (2), in 1964, is still currently accepted to explain the relationship between pain of dentinal origin and the displacement of odontoblasts in the dentinal tubules. Thermal, physical and chemical stimuli would cause the displacement of the pulp-dentinal fluid, thus stimulating the pulpar nervous terminations.

Under normal conditions, dentine is covered by enamel or cement and does not suffer direct stimulation. Only with the exposure of the peripheral terminations of dentinal tubules is a situation of strong dentinal sensitivity manifested, termed hypersensitivity. Occlusion of the exposed dentinal tubules can reduce the intensity of dentinal sensitivity. This can be accomplished through passive mechanisms, such as precipitation of salivary calcium phosphate inside the dentinal tubules, adsorption of plasma proteins and saliva constituents, as well by active mechanisms such as deposit of intracanalicular crystalline material and secretion of 
protein material from the interior of the tubules, diminishing dentinal permeability and sensitivity (3).

Type A fibers are responsible for dentinal sensitivity and are probably activated by the hydrodynamic mechanism. Therefore, their activation is directly associated to the presence of opened or occluded tubules. However, hypersensitivity sometimes remains in spite of the effective blocking of the tubules, suggesting that other mechanisms contribute to nerve activation instead of or in addition to the hydrodynamic mechanism. Dentine hypersensitivity may occur as a result of sensitization induced by nerve inflammation in the dentinepulpar boundary of teeth with opened dentinal tubules. This partially explains the large sensitivity variation of exposed dentine and, furthermore, nerve activation may result in the release of neuropeptides from the activated nervous terminations and, consequently, induce neurogenic inflammation. The symptoms of dentine hypersensitivity would, up to a certain point, be self-sustainable (4).

The most common factors responsible for dentine hypersensitivity are abrasion, caused by toothbrushing with inadequate intensity; abfraction, caused by tooth flexion associated with ill-directed occlusal forces, parafunctional habits or occlusal disequilibrium; erosion, as an effect of acids in the oral cavity; anatomic predisposition due to structural deficiency in the enamel-cement junction; cavity preparations in teeth with pulp vitality that expose the dentine; as well as improperly controlled dentinal acid conditioning $(5,6)$.

Any treatment, which reduces the dentinal permeability, must diminish dentinal sensitivity. The occlusion of dentinal tubules leads to reduction of dentinal permeability and, proportionally, also decreases the degree of dentinal sensitivity (7). According to the hydrodynamic theory, the effectiveness of dentine desensitization agents is directly related to their capacity to promote the sealing of the dentinal canaliculi (8).

With the advent of laser technology and its growing utilization in dentistry, an additional therapeutic option is available for the treatment of dentinal pain. The laser, by interacting with the tissue, causes different tissue reactions, according to its active medium, wavelength and power density and to the optical properties of the target tissue (9).

The laser photobiomodulating action in the dental pulp was reported by Villa et al. (10), with histological studies of dental pulp of mice after irradiation with laser, in teeth previously eroded with high rotation in order to expose the dentine. The profiling of the odontoblasts was observed, showing evidence of a large quantity of tertiary dentine production, causing the physiological obliteration of the dentinal tubules. The non-irradiated control teeth showed intense inflammatory process that, in some cases, evolved to necrosis.

The effectiveness of dentine hypersensitivity treatment with diode laser, with different wavelengths, has been reported in various clinical studies. Matsumoto et al. (11) found $85 \%$ improvement indexes in teeth treated with laser; Aun et al. (12) reported successful treatment in laser irradiated teeth in $98 \%$ of the cases; Yamaguchi et al. (13) reported effective improvement index of $60 \%$ in the group treated with laser and only $22.2 \%$ in the control group; Kumazaki et al. (14) showed an improvement of $69.2 \%$ in the group treated with laser compared to $20 \%$ in the placebo group; Gerschman et al. (15), in a double-blind study, found significant values in the treated group in relation to the placebo group: sensitivity to thermal stimuli was reduced by $67 \%$, whereas the placebo group had a reduction of $17 \%$, sensitivity to tactile stimuli was reduced by $65 \%$, while the placebo group showed a reduction of $21 \%$.

The immediate analgesic effect in the treatment of dentine hypersensitivity with diode laser was reported by Brugnera Júnior et al. (16) with an improvement index of $91.29 \%$ in 1102 treated teeth, operating in different bands of wavelength, $780 \mathrm{~nm}$ and $830 \mathrm{~nm}$, and different power densities of $40 \mathrm{~mW}$ and $50 \mathrm{~mW}$, but maintaining the same energy density deposited per dental element of $4 \mathrm{~J} / \mathrm{cm}^{2}$.

According to the consulted literature, both red and infrared wavelength lasers have been effective in the treatment of dentine hypersensitivity. They are physical methods which, even operating at different bands of wavelength, cause the dentine-pulp complex to respond to the irradiation with the obliteration of the dentinal tubules by the means of specific biological mechanism. The laser interaction with the dental pulp causes a photobiomodulating effect, increasing the cellular metabolic activity of the odontoblasts and obliterating the dentinal tubules with the intensification of tertiary dentine production.

The need for clarification regarding the specification of dosimetry parameters for laser irradiation applied in dentine hypersensitivity treatment is increas- 
ing due to the large variety of lasers currently available (17). Thus, the purpose of this study was to evaluate the effectiveness of two types of lasers, one with red wavelength of $660 \mathrm{~nm}$ and the other with infrared wavelength of $830 \mathrm{~nm}$, as dentine desensitizers as well as the immediate and late effects in adult individuals of different ages.

\section{MATERIAL AND METHODS}

A total of 40 teeth from 20 adult individuals (9 male and 11 female; aged 25 to 45 years) with a diagnosis of odontalgia of dentinal origin and cervical dentine exposure were treated. Approval by the Ethics Committee and informed written consent was obtained at the clinic of otorhinolaryngology discipline of the Escola Paulista de Medicina of UNIFESP. The teeth included in the sample were absent of bacterial infection, were at the prodromal stage of the inflammatory lesion with intense and short positive response to cold nociceptive stimulus of $0^{\circ} \mathrm{C}$.

The thermal test with cold stimulus was performed by the contact to the cervical dentinal surface with a flexible stick applicator, cooled with EndoFrost $^{\circledR}$ (Roeko, Langenau, Germany). In order to standardize the sample, the criterion for inclusion in the study was a sensitive dentinal response of grade 10 , in the 0 to 10 numeric scale for pain evaluation, characterizing cervical dentine hypersensitivity. The treated dental elements were premolars, did not have ample restorations and the individuals included in the sample showed an absence of active periodontal disease, teeth with carious lesions, chronic or debilitating disease with daily pain episodes, no use of analgesic, anticonvulsive, antihistaminic, sedative, tranquilizing or antiinflammatory medications in the $72 \mathrm{~h}$ preceding treatment, had not used desensitizer dentrifice in the last 3 months and had not been subjected to periodontal surgery in the last 6 months.

The sample was divided into 2 groups of 20 teeth: the red laser group and the infrared laser group. The applied laser device was the Laser Beam DR 500 Power, with two straight-type pens of GaAlAs diode laser; one with nominal wavelength of $660 \mathrm{~nm}$ and verified wavelength of $660.14 \mathrm{~nm}$, red, nominal power of $35 \mathrm{~mW}$ and verified power of $35.22 \mathrm{~mW}$, focus dimension of $1 \mathrm{~mm}^{2}$ with elliptical standard and the other with nominal wavelength of $830 \mathrm{~nm}$ and verified wavelength of $830.05 \mathrm{~nm}$, infrared, nominal power of $35 \mathrm{~mW}$ and verified power of $35.30 \mathrm{~mW}$, focus dimension of $1 \mathrm{~mm}^{2}$ with elliptical standard, manufactured by Laser Beam Indústria e Tecnologia (Niterói, RJ, Brazil).

As a study factor, the sample was also divided into 2 subgroups according age, one group consisted of 25-35-year-old individuals and the other of 35-45-yearold individuals.

This study was performed by one operator and one assessor responsible for the measurement of the pain level of the patients. The treatments were carried out in 4 sessions, with intervals of 7 days between sessions, during a period of 4 consecutive weeks.

The sample was evaluated through the measuring of the dentinal sensitive response to the cold nociceptive stimulus of $0^{\circ} \mathrm{C}$, with a numeric scale from zero to 10 . The measurements were performed before each treatment session and at 15 and $30 \mathrm{~min}$ after the laser application to verify the capacity, the extent, and the duration of desensitization after irradiation. This result was called immediate effect. Additional measurements were also performed at 15,30 and 60 days after the conclusion of treatment in order to assess the extent of desensitization obtained at the different wavelengths. This result was called late effect.

The dentinal cervical region of the treated teeth exposed to the buccal medium was previously cleaned. Afterwards, relative isolation of the region was carried out with the aid of a cotton roll and the drying of the buccal surface with gauze before each treatment session.

The irradiation parameters were identical, except in respect to the wavelength - one of $660 \mathrm{~nm}$ and other of $830 \mathrm{~nm}$. The deposited energy density was $4 \mathrm{~J} /$ $\mathrm{cm}^{2}$ per dental element with exposition time of 114 seconds, continuous emission form, punctual application in the buccal surface and application with contact on the region of exposed dentinal neck.

In the descriptive statistical analysis, all of the studied variables were described in relation to the mean and standard. In order to compare the studied factors, ANOVA was applied for the following factors: a) dependent factor - quantitative numeric pain scale; $b$ ) independent factors - age (25-35 years; 36-45 years) and groups ( $660 \mathrm{~nm}$ red laser; $830 \mathrm{~nm}$ infrared laser); c) repetitive factors - treatment sessions (first, second, third and fourth), immediate effect (BT - before treat- 
ment, 15 and 30 min after irradiation) and late effect $(15,30$ and 60 days after conclusion of treatment). The significance level of the test was $5 \%$.

\section{RESULTS}

Significant reduction of dentinal sensitivity occurred along all times measured during the four treatment sessions in both groups treated with red and infrared lasers. Comparing the means of the responses in the 4 treatment sessions of the 2 groups, the red laser group showed a higher degree of desensitization in the age range of 25 to 35 years compared to the group treated with infrared laser. However, a greater reduction was found between the times BT and 15 min after irradiation with red laser. These results remained stable between 15 and 30 min after irradiation in patients 25-35 years of age, whereas, in the 36-45-year-old group, sensitivity increased slightly after 15 min of irradiation.

In the follow-up period of 15, 30 and 60 days after the conclusion of treatment, the age range of 25 to 35 years presented the higher dentinal desensitizing index, giving responses with more significant results in

Table 1. Values (means $\pm \mathrm{SD}$ ) of dentinal sensitive response of the $660 \mathrm{~nm}$ red laser treatment group.

\begin{tabular}{ccc}
\hline & 25 -35-years-old & 36-45-years-old \\
\hline Immediate effect & & \\
$1^{\text {st }}$ session & & \\
BT & $10.00 \pm 0.00$ & $10.00 \pm 0.00$ \\
15 min & $3.00 \pm 1.51$ & $5.00 \pm 1.91$ \\
30 min & $3.88 \pm 2.17$ & $6.08 \pm 2.07$ \\
$2^{\text {nd }}$ session & & \\
BT & $6.50 \pm 2.33$ & $8.33 \pm 1.50$ \\
15 min & $1.13 \pm 1.13$ & $4.08 \pm 2.64$ \\
30 min & $1.38 \pm 1.30$ & $4.92 \pm 2.64$ \\
$3^{\text {rd }}$ session & & \\
BT & $2.63 \pm 1.69$ & $6.42 \pm 2.19$ \\
15 min & $0.38 \pm 0.52$ & $3.17 \pm 2.72$ \\
30 min & $0.38 \pm 0.52$ & $4.08 \pm 2.87$ \\
$4^{\text {th }}$ session & & \\
BT & $1.25 \pm 0.71$ & $5.00 \pm 3.22$ \\
15 min & $0.38 \pm 0.52$ & $2.50 \pm 2.91$ \\
30 min & $0.38 \pm 0.52$ & $3.33 \pm 3.26$ \\
Late effect & & \\
15 days & $1.13 \pm 1.13$ & $4.33 \pm 3.63$ \\
30 days & $1.13 \pm 0.99$ & $5.00 \pm 3.79$ \\
60 days & $0.75 \pm 0.89$ & $5.25 \pm 3.82$ \\
\hline
\end{tabular}

both of the groups.

The results of treatment with the $660 \mathrm{~nm}$ red laser and the $830 \mathrm{~nm}$ infrared laser are reported in Tables 1 and 2. Statistical results are reported in Table 3.

\section{DISCUSSION}

The literature is unanimous in demonstrating that, even with several types of treatment for dentine hypersensitivity, there is no treatment that reduces pain to satisfactory levels. According to Landry and Voyer (18), there is no ideal desensitizing agent but any treatment method for dentine hypersensitivity should be effective from the first application and must comply with the following characteristics: does not irritate the pulp or cause pain, easy application, effective on a permanent basis, does not discolor or stain the teeth, does not irritate the soft tissues or the periodontal ligament and has low cost.

Cervical dentine hypersensitivity has multifactorial etiology and generally more than one factor is found associated and active in this painful manifestation. Therefore, more than one treatment method should

Table 2. Values (means $\pm \mathrm{SD}$ ) of dentinal sensitive response of the $830 \mathrm{~nm}$ infrared laser treatment group.

\begin{tabular}{ccc}
\hline & $25-35$-years-old & 36-45-years-old \\
\hline Immediate effect & & \\
$1^{\text {st }}$ session & & \\
BT & $10.00 \pm 0.00$ & $10.00 \pm 0.00$ \\
15 min & $5.13 \pm 2.10$ & $7.42 \pm 1.83$ \\
30 min & $5.88 \pm 1.96$ & $8.58 \pm 1.38$ \\
$2^{\text {nd }}$ session & & \\
BT & $8.13 \pm 1.89$ & $9.83 \pm 0.39$ \\
15 min & $2.75 \pm 1.58$ & $6.83 \pm 2.29$ \\
30 min & $3.50 \pm 2.14$ & $8.08 \pm 1.88$ \\
$3^{\text {rd }}$ session & & \\
BT & $4.75 \pm 2.66$ & $8.50 \pm 1.45$ \\
15 min & $1.87 \pm 1.36$ & $5.58 \pm 2.47$ \\
30 min & $2.38 \pm 1.92$ & $6.58 \pm 2.31$ \\
$4^{\text {th }}$ session & & \\
BT & $3.13 \pm 1.96$ & $7.08 \pm 2.50$ \\
15 min & $1.00 \pm 0.93$ & $4.50 \pm 2.88$ \\
30 min & $1.38 \pm 1.19$ & $5.25 \pm 2.83$ \\
Late effect & & \\
15 days & $2.50 \pm 2.27$ & $6.25 \pm 3.55$ \\
30 days & $2.75 \pm 2.71$ & $6.58 \pm 3.40$ \\
60 days & $2.38 \pm 2.39$ & $6.67 \pm 3.60$ \\
\hline
\end{tabular}


be associated to desensitize the dentine to satisfactory levels. According to Garone Filho (6), the most common etiological factor related to clinical manifestations of dentine hypersensitivity is the abfraction caused by occlusal overload. The premolars are the more affected teeth and, in almost all of the cases of dentine hypersensitivity, there is an occlusal component. Thus, occlusal adjustment should be associated to any kind of desensitizing agent selected for the treatment of hypersensitivity.

In the present study, the dentinal sensitive response to the cold nociceptive stimulus was evaluated in teeth, which initially had a pain intensity response of grade 10 , maximum pain in the quantitative numeric pain intensity scale. The selected individuals had similar socio-cultural characteristics, which increases the dependability degree of the assessment.

Matsumoto et al. (19) reported good results in patients treated with red and infrared lasers who initially presented light and moderate pain levels. The treatment had not been effective in the cases that had shown maximum initial level of pain.

The treatments performed with lasers at different bands of red and infrared wavelength demonstrated a certain degree of dentinal desensitizing capacity, but the results obtained in this study made evident that satisfactory desensitizing levels were only found in patients ranging in age between 25 and 35 years, with the $660 \mathrm{~nm}$ red laser more effective than the $830 \mathrm{~nm}$ infrared laser. A higher degree of desensitization was also observed at 15 and $30 \mathrm{~min}$ after irradiation. Aun et al. (12) also observed reduction in pain intensity shortly

Table 3. Analysis of Variance (ANOVA) for age, treatment group and treatment session factors.

\begin{tabular}{|c|c|c|c|c|c|c|}
\hline Effect & $\begin{array}{c}\text { Effect } \\
\text { Freedom } \\
\text { Degrees }\end{array}$ & $\begin{array}{l}\text { Effect } \\
\text { Mean } \\
\text { Square }\end{array}$ & $\begin{array}{c}\text { Error } \\
\text { Freedom } \\
\text { Degrees }\end{array}$ & $\begin{array}{c}\text { Error } \\
\text { Mean } \\
\text { Square }\end{array}$ & $\mathrm{F}$ & $\begin{array}{c}\text { Significance } \\
\text { of } F\end{array}$ \\
\hline \multicolumn{7}{|c|}{ Immediate effect } \\
\hline Age & 1 & 981.167 & 18 & 63.6864 & 15.4062 & $0.0010 *$ \\
\hline Group & 1 & 386.467 & 18 & 3.7374 & 103.4063 & $<0.0001 *$ \\
\hline Series & 3 & 381.659 & 54 & 3.8631 & 98.7950 & $<0.0001 *$ \\
\hline Moments & 2 & 542.872 & 36 & 4.0669 & 133.4843 & $<0.0001^{*}$ \\
\hline \multicolumn{7}{|l|}{ Late effect } \\
\hline Age & 1 & 440.235 & 18 & 53.4147 & 8.2418 & $0.0102 *$ \\
\hline Group & 1 & 72.835 & 18 & 2.6184 & 27.8161 & $<0.0001^{*}$ \\
\hline Moments & 2 & 0.972 & 36 & 0.1590 & 6.1165 & $0.0052 *$ \\
\hline
\end{tabular}

after irradiation with red laser with wavelength of 632.8 $\mathrm{nm}$, active medium HeNe. We believe that this desensitizing effect obtained after irradiation with diode lasers at both wavelengths of $660 \mathrm{~nm}$ and $830 \mathrm{~nm}$ is a result of suppression of the evocated potential of the pulp nociceptive nervous fibers.

The morphology of the pulp-dentine complex in patients between 25 and 35 years of age, when compared to patients between 36 and 45 years of age, may be a determinant factor for tissue response. Regressive or atrophic alterations in the dentine-pulp complex, such as the presence of a higher quantity of reactional dentine, decrease of cellular components, increase in number and thickness of collagenous fibers, diminution of the number and size of odontoblasts and atresia of the neurovascular bundle, are resultant of the physiological process of ageing and of pathological processes.

According to Pashley (7), there are two types of dentinal permeability: intratubular, which occurs inside the dentinal tubules, and intertubular, which is found between the tubules in the dentinal matrix. The sensitive dentine is permeable across its thickness; any treatment that reduces dentinal permeability must reduce dentinal sensitivity. The higher the diffusion capacity of dentine, the higher will be the interaction of the desensitizing agent.

Occlusion of the exposed dentinal tubules may decrease the dentinal sensitivity level (3-8). However, the hypersensitivity may sometimes persist in spite of effective blocking of the tubules, thus indicating that other mechanisms may act in nerve activation instead of or in addition to the hydrodynamic mechanism, such as the release of neuropeptides from the activated nervous terminations and, consequently, the induction of a neurogenic inflammation; thus signifying that the symptoms of dentine hypersensitivity could, up to a certain point, be self-sustainable (4).

Histological analyses of the dental pulp, in a experimental study carried out by Matsumoto et al. (20) in teeth previously prepared with the aid of high rotation, have shown a better degree of repair at 14 and 30 
days after laser irradiation when compared with the non-irradiated dental pulp group. Villa et al. (10) observed the profiling of odontoblasts and a large quantity of neoformed tertiary dentine in irradiated teeth, previously eroded by high rotation. The non-irradiated group showed intense inflammatory process and in some cases evolved to irreversible pulp degeneration and necrosis. The laser irradiation contributed to the repair of the dentine-pulp complex, preserving the pulpar vitality.

Wavelengths of $632.8 \mathrm{~nm}$-active medium $\mathrm{HeNe}$, used by Matsumoto et al. (19), Aun et al. (12), and GaAlAs diodes with wavelengths of $780 \mathrm{~nm}, 790 \mathrm{~nm}$ and $830 \mathrm{~nm}$ used by Kumazaki et al. (14), Yamaguchi et al. (13), Gerschaman et al. (15), and Brugnera Júnior et al. (16) demonstrated the capacity of reducing the intensity of the pain of dentinal origin.

Pinheiro (9) reported that the tissue response after irradiation is determined by factors which are inherent to the laser, such as its active medium, wavelength, power density, emission mode and application method and by the optical properties of the target tissue. Through multiple comparisons, the present study demonstrated that at all times the age range of 25 to 35 years treated with red laser presented a higher degree of dentinal desensitization. The lower degree of dentinal desensitization observed in 36-45-year-old patients may be a result of the presence of a higher quantity of intertubular dentine and the smaller lumen of the dentinal tubules. The path of the laser beam though the dentinal tissue until the pulp, the laser diffusion and absorption capacity of the dentinepulp complex and the sensitization of the peripheral pulpar nervous terminations that are in close relation with the odontoblasts may suffer variations as a result of morphologic alterations of the dental structure.

Based on the results obtained in the treatment of 40 teeth with cervical dentine hypersensitivity, having initial response of pain intensity of grade 10 in the quantitative numeric pain scale (maximum of the pain scale), we conclude that: 1) the $660 \mathrm{~nm}$ red diode laser was effective as a dentine desensitizer in 25-35-yearold adult patients, whereas in 36-45-year-old patients its action was moderate; 2) the $830 \mathrm{~nm}$ infrared diode laser had moderate effectiveness in 25-35-year-old adult patients, whereas in 36-45-year-old patients it was ineffective; 3 ) the therapeutic immediate and late effects of the $660 \mathrm{~nm}$ red diode laser were greater than those of the $830 \mathrm{~nm}$ infrared diode laser at both age ranges.

\section{RESUMO}

A hipersensibilidade dentinária cervical é a queixa mais frequente entre os relatos de odontalgia. Este estudo avaliou a eficácia de dois tipos de lasers, vermelho com 660nm e infravermelho com $830 \mathrm{~nm}$ de comprimento de onda, como dessensibilizadores dentinários, como também os efeitos terapêuticos imediato e tardio em indivíduos de 25 a 45 anos de idade. Um total de 40 dentes com exposição cervical foram tratados em 4 sessões, divididos em 2 grupos - laser vermelho e infravermelho. A sensibilidade dentinária ao estímulo nociceptivo frio foi avaliada por meio de uma escala numérica de dor, de 0 a 10, antes de cada sessão de tratamento, aos 15 e 30 minutos após a irradiação e num período de seguimento de 15,30 e 60 dias após o término do tratamento. Níveis significantes de dessensibilização dentinária foram apenas encontrados em pacientes com idade entre 25 a 35 anos. O laser díodo vermelho de $660 \mathrm{~nm}$ foi mais eficaz comparado com laser infravermelho de $830 \mathrm{~nm}$ e foi observado um nível mais alto de dessensibilização nas mensurações realizadas aos 15 e 30 minutos após irradiação. $\mathrm{O}$ efeito terapêutico imediato e tardio do laser díodo vermelho de $660 \mathrm{~nm}$ é maior quando comparado com o infravermelho de $830 \mathrm{~nm}$ em ambas faixas etárias.

\section{ACKNOWLEDGEMENTS}

This work was supported by a CAPES research grant and the Federal University of São Paulo - UNIFESP. We acknowledge the Laser Solutions Tecnologia for the use of the Laser Beam 500, and Reinaldo Leite for his valuable technical assistance.

\section{REFERENCES}

1. Brugnera Júnior A, Zanin F. Sensibilidade dentinária - tratamento através do laser. In: Dor Orofacial / ATM - Bases para o diagnóstico clínico. Siqueira JTT, Ching LH. eds. Curitiba: Maio; 1999. p 181-187.

2. Brännstrom $\mathrm{M}$, Aström A. A study of the mechanism of pain elicited from the dentin. J Dent Rest 1964;63:619.

3. Pécora JD. Complexo dentina-polpa. Medcenter.com Odontologia 2001; <www.forp.usp.br/restauradora/dentin.html>.

4. Närhi M, Kontturi-Närhi V, Hirvonen T, Ngassapa D. Neurophysiological mechanisms of dentin hypersensitivity. Proc Finn Dent Soc 1992;88:15-22.

5. Brännstrom M. Etiology of dentin hypersensitivity. Proc Finn Dent Soc 1992;88:7-13.

6. Garone Filho W. Lesões cervicais e hipersensibilidade dentinária. In: Atualização na clínica odontológica: a prática na clínica geral. Todescan FF, Bottino MA. eds. São Paulo: Artes Médicas; 1996. p 35-73.

7. Pashley DH. Dentin permeability and dentin sensitivity. Proc Finn Dent Soc 1992;88:31-37.

8. Ling TY, Gillam DG. The effectiveness of desensitizing agents for the treatment of cervical dentine sensitivity (cds) a review. J West Periodontol Periodontal Abstr 1996;44:5-12.

9. Pinheiro ALB. Interação tecidual. In: Lasers na Odontologia Moderna. Brugnera Jr A, Pinheiro ALB. eds. São Paulo: Pancast; 1998. p 45-62.

10. Villa RG, Brugnera Jr A, Aun CE. Estudo histológico da atuação do raio laser He:Ne na neoformação dentinária em polpa de ratos. 
V Oncris SBPq 1988; p 101.

11. Matsumoto K, Tomonari H, Wakabayashi H. Study on the treatment of hypersensitive dentine by laser. J Conservat Dent 1985;28:1366-1371.

12. Aun CA, Brugnera Júnior A, Villa RG. Raio laser Hipersensibilidade dentinária. Revista da APCD 1989;43(2):6568.

13. Yamaguchi M, Ito M, Miwata T, Horiba N, Matsumoto T, Nakamura H, Fukaya M. Clinical study on the treatment of hypersensitive dentin by GaAlAs laser diode using the double blind test. Aichi-Gakuin J Dent Sci 1990;28:703-707.

14. Kumazaki M, Zennyu K, Inoue M, Fujii B. Clinical evaluation of GaAlAs-semiconductor laser in the treatment of hypersensitive dentin. Japan J Conservative Dentistry 1990;33:911-918.

15. Gerschman JA, Ruben J, Gebart-Eaglemont J. Low level laser therapy for dentinal tooth hypersensitivity. Aust Dent J 1994;39:353-357.

16. Brugnera Júnior A, Zanin F, Pinheiro A, Pécora J, Ladalardo TC,
Campos D, Garrini, A, Donamaria E, Cruz F, Takamoto M. LLLT in treating dentinary hypersensibility: a histologic study and clinical application. Second International Conference on Near-Field Optical Analysis: Photodynamic Therapy \& Photobiology Effects Houston, Texas, USA, May 31 - June 1, 2001. Proceedings of the Second International Conference on NOA, 2002. p 23-31.

17. Kimura Y, Wilder-Smith P, Yonaga K, Matsumoto K. Treatment of dentine hypersensitivity by lasers: a review. J Clin Periodontol 2000;27:715-721.

18. Landry RG, Voyer R. Le traitement de l' hypersensibilité dentinaire: Une étude rétrospective et comparative de deux approches thérapeutiques. J Can Dent Assoc 1990;56:1035-1041.

19. Matsumoto K, Nakamura G, Tomonari H. Study on the treatment of hypersensitive dentine by HeNe Laser irradiation. J Conservat Dent 1986;29:312-317.

20. Matsumoto K, Wakabayashi H, Funato A, Shirasuga T. Pathohistologic findings of dental pulp irradiated by GaAlAs laser diode. J Conservat Dent 1985;28:1361-1365.

Accepted March 15, 2004 